\title{
THE CONCEPTION OF THE UNIVERSAL DUAL CATEGORIES OF WISDOM IN MOVSES KHORENATSI'S DOCTRINE OF HISTORY
}

\begin{abstract}
The author of this article presents a system of 12 dual categories of the philosophy of history first outlined in his monograph dedicated to the study of the philosophical-methodological aspects of Movses Khorenatsi's great work "The History of Armenians". The system of 12 dual categories of the wisdom of history suggested by the author of this article demonstrates that Movses Khorenatsi's theory of history builds a firm conception of philosophizing "science of history".
\end{abstract}

Keywords: history, philosophy of history, wisdom, category, conception, understanding, interpretation.

\section{Introduction}

The problem of categories comes from Aristotle's work under the same title (see Ackrill, 1963). Aristotle suggested here ten basic notions for describing any object of human apprehension: substance, quantity, qualification, a relative, where, when, being-in-a-position, having, doing, being-affected (Categories, 1b25-2a4). Aristotelian categories are generally conceived as a list of the highest genera of beings (see Carr, 1987). From the realist approach, categories of philosophy are conceived as the central problem of ontology (see Grossmann, 1983). One can note the realistic approach to categories is present also in metaphysics: "the differentiae of any genus must each of them both have being and be one" (Aristotle, Metaphysics, 998b22-3). It should be mentioned also that neither Aristotle nor other prominent researchers had explicitly investigated the task of demonstrating the completeness of the suggested systems of categories (see Studtmann, 2007).

Emanuel Kant radically changed the interpretation of the essence of categories, presenting them as a priori necessary conditions for any possible cognition of objects (see Kant, 1958/1781). One can have a priori knowledge by means of the categories, only if the categories are due to the nature of the mind and are imposed by the mind on the objects which it knows (see Paton, 1936). Later generations of philosophers preferred to approach the problem of categories in a neutral spirit refraining from ontical interpretations (see Carr, 1987).

This "neutral approach" is transformed into a principle by Edmund Husserl. He put the emphasis on the meanings of categories which may then be used to draw out ontological categories as the correlates of the meaning catego- 
ries. In contrast to traditional approaches, Husserl never demonstrated concern for any empirical matter about whether or not there are objects of the various ontological categories (see Thomasson, 2018).

Amie Thomasson has justly mentioned that philosophers suggesting a system of categories face a variety of difficulties. Namely, they must address the issue of what the proper methods are by means of which categories are to be distinguished, how many categories there are and what they are, whether or not there is a single summum genus subsuming all other categories, and whether we should distinguish a single system of categories or multiple dimensions of categories. Possibly, it is quite reasonable to investigate categories as such, not getting involved in meta-theoretical discussions (see Hoffman \& Rosenkrantz, 1994).

In the fundamental work of Movses Khorenatsi (2006) "The History of Armenians" the being of history is revealed not merely as an empiric history, but rather as present in it human and in particular Armenian identity, life and culture including science of history, by means of self-understanding wisdom, thus with contained in it problematic and deliberations, and in essence, with thinking deserving its high calling it appears also as historical wisdom accepted in scientific publications as historicalscientific conception mainly due to its astounding perfection and instructive quality. "According to his historical-scientific and historicalphilosophical conception, the true presence of history is the presence of wisdom embodied and contained in history for the identity and life of "reading-loving" and "study-loving" contemporaries” (Kocharyan, 2016 a , p. 491).

Indeed, according to the historical-scien- tific conception of Khorenatsi, the true presence of history is the symbolically contained presence of wisdom in the significant events of human identity, life and culture in the present and future of "reading and study lovers", in the identity and life of contemporaries and coming generations. One can fix in detail that "the calling of the being of history and its participation in the life of humanity, and respectively, the true intention and realization of history and its essential presence are understood and interpreted as the presence of wisdom formed and contained in history in the name of perfection of the identity, lifestyle and culture of "reading and study lover" contemporaries and coming generations" (Kocharyan, 2016 a , pp. 491-492).

In my studies querying the wisdom shaped and contained in the history of Movses Khorenatsi, and summing up and rethinking the results of the investigation, I have concluded that the wisdom of his historical doctrine is disclosed by the twelve dual categories indicating its inner dichotomy and bi-unity, which is presented not only as the achievement and the result of investigation but also as an essential component of the methodological conception applied in my studies. Moreover, with substantiation it is also fixed, that the wisdom available for human capacity, not only in historical science, but - in virtue of universality inherent to it in principle - in all fields of human life and activity as well as in all sciences reaches the completeness of its fullness by the twelve dual categories. "Studying the wisdom of "the science of history" of Movses Khorenatsi, and also immediately applying it, the presence of wisdom for human self-identity and life reaching to the completeness of wisdom's fullness with this kind order - in my (above cited) 
monograph is interpreted as the universal methodological conception for studying and disclosing the very truth of being of all entity, and adequately to it - of the wisdom of science and activity, available for human capacity" (Kocharyan, 2016 a, pp. 626-627).

So what is the wisdom revealing the truth of the being of history as such that is theoretically-conceptually embodied and chosen from the significant fulfilment of the self-identity, life and culture of Armenian people in the history of Movses Khorenatsiand understood as the wisdom of his historiosophy? What is the wisdom of his historical science by its inter-related properties and components understood and interpreted with the help of the twelve dual categories and by that present and expressed by inner dichotomy and twofold-unity of its essence? And in particular, which are the twelve dual categories revealing the unified-whole wisdom of the "science of history" of Movses Khorenatsi?

1. In cognition of things and understanding events of human acts in all sciences are investigated the being of the particular and general, e.g. the concrete being of the given entity and as such the being of the general nature of this existence, revealing their "what" and "how" exposing wisdom which by that is understood and interpreted by dual categories expressed by their components of inner dichotomy and twofold-unity.

The revelation of the truth of the being of things acts, phenomena and also of history can be understood as the revelation of the truth not only principally of the being of history as such, but also of its singular and unique being. In the given study by this formulation of the problem and only in this measure of the definition of the "history" of the required unknown and of the demand of this unknown the expected answer is thought over as a particular solution. Indeed, to reveal the truth of being of any existing thing, humanitarian, social or of any other phenomenon means the revealing of their nature in all the specificity of their singular, concrete and particular, unique and individual modes of being - in the interwoven wholeness of their specifically expressed and fulfilled particularities, that can be definitely understood as the revelation of the just one among the other possible real and concrete modes of being of each one in the dimension of time.

In our study, this kind of revelation of the nature of the own special way of the being of history is carried on by investigating the work "History of Armenians" of Movses Khorenatsi and in it the truth of being of history as such, and interpretatively explicating the specificity of his Christian conception of history. But we consider such formulation of the task of the undertaken research as a particular case, and our investigation by its intention and fulfilment is not either limited or satisfied by this extent of revelation. The intention of this article formed as a whole complex of the inner ordered and interwoven components is perceived the principle problem of revealing the truth of the nature of history, in other words, of the being of history as such.

2. Human being is a cognizing and selfcognizing and/or understanding and selfunderstanding creature, and all the accessible to human capacities wisdom reaches its completeness with the help of the inter-complementary dual components presented by the following dual categories - understanding (of others) and self-understanding, or cognition (of others) and self-cognition, and by that the wisdom appears 
with its inner dichotomy and twofold-unity. Thus all the science as such and the contained in it wisdom appear with the help of dual categories by their inner dichotomy and interwoven twofold-unity: for natural sciences - by cognition and self-cognition, for human and social sciences - by understanding and selfunderstanding.

One can add also, that understanding (cognition) of others in its maximally all-embracing meaning can be considered as self-understanding (self-cognition). Therefore we'll deal just and only with self-understanding (self-cognition) and with the contained in it wisdom present with its two-component dual categories. How it can be? Natural sciences investigate the material world inorganic, organic, plants and animals - and by revealing the truth of being that is characteristic just to their nature, they also investigate and reveal the wisdom contained in the truth of the world. Hear, in essence, as "self-understanding" appears the understanding (or cognition) of the universal-general and particular qualities of the material, organic and animal, which are contained in these all the existence and build the human spiritual-bodily nature, carrying his rational soul in them, and just this kind of selfunderstanding creates the natural science as such. Human and social sciences investigate and reveal the truth of purely human things in their truly human and different from all other existences by their spiritual nature, by understanding and interpretation of its properties that realize psychic, social, cultural, civilizational dimensions, components and qualities of the inner and outer spheres of human being: self-identity and lifemode, and just this kind of self-understanding creates human and natural sciences as such. At the same time in natural sciences as well as in human sciences or social sciences is realized the self-understanding of the theory itself, with the help of which these sciences are developed and brought to completion as capable of understanding and interpreting, and therefore containing in themselves the truth of human self-identity, life and culture.

Thus, in the "science of history" of Movses Khorenatsi the being of history is such, those inner queries have already got in it essential significance too, and history is becoming one, which understands and interprets significant being of human, and in it Armenian, identity, life-mode and culture, as well as it self-understands and self-interprets by itself its being, truth and meaning, and so it exists as a selfunderstanding and self-interpreting phenomenon. His "theory of history" is not presented and identified only as a theory describing the bygones (or yore) of Armenian life and also its practice, and as such - just a "collection of observations". Together with understanding, already by its self-understanding feature too, the history of Khorenatsi has also the quality of theorizing its nature. His history conceives the authentic destiny of its being, as well as the meaning indicating the truth of its own being adequate to the recognized destiny. In this connection, it should be noted, that in history of historiography, there are also many other conceptions differently understanding and interpreting the destiny of history. In such way the conception of the "science of history" of Movses Khorenatsi having necessary for science general feature, in it and/or by it indicates its principal and essential property of "self-understanding" too, which develops his conception on the path to the perfection of knowledge, possible for "science of history". The history of Movses Khorenatsi by its "self- 
understanding" feature contains in itself the comprehension of the meaning which reveals the truth of its being corresponding to its destiny, and rising up by pondering over the counsel of wisdom contained in that meaning, in this modus of its being internally becomes and is cognized as a true "science of history", that contains in itself the truth and wisdom of its own being corresponding to its genuine destiny.

Thus, the second dual category that with inner dichotomy and unity presents and interprets the wisdom of the historical-scientific conception of Movses Khorenatsi is defined in the formation of the history as such by the components of "understanding" and "self-understanding", or just by two modes of "self-understanding".

Which is concretely the wisdom of the history of Khorenatsi itself appearing by twofold components as "understanding" and "self-understanding" or by two-meaning modes of "self-understanding"? The first, Khorenatsi in his work and/or by his work realizes the understanding of the "becoming of the nature of human and in it Armenian self-identity, life and culture", which can be identically re-understood and re-interpreted as self-understanding, and just by this way is created and born history. Because for the history and concretely for the Armenian history of Movses Khorenatsi and also for the entire social science to understand the truth of the human and concretely of Armenian self-identity, life and culture means to realize the self-understanding of the common spiritual- and life-experience of the national and personal self-identity, life and creative-cultural capabilities both by the self-becoming way and the virtues for perfection and ascending, as well as by passions, obsessions and vices of seduction, stumbling and perdition.
And the second modus of the self-understanding is that the Father of Armenian History in his treatise realizes also the self-understanding of the principle possibility of the "science of history" and thus creates "the theory of history" capable by its adequate openness to perceive in itself, comprehend by understanding and explicate by interpretation this same substantive and objective truth of human self-identity, life and culture. Thus self-understanding is the basis not only for the principle genesis of history but also for the process of its self-perfection and self-becoming as of the "science of history".

We would like to mention also that this study of the Khorenatsi theory of history the "object of the query" - the being of the history as such discloses not only as an ontical unit - as a purely empiric (the description and fixation of bygone, yore) historiography. The being of history as such is disclosed also as the questioning of its own being by revealing the sense (meaning) and understanding-theorizing its nature and as self-understanding "theoretical activity" and just as science, that is in self-reflection of its content - ontical and empirical history, already as an ontological unit.

So, in the historical-scientific conception of Movses Khorenatsi the nature of history or being of history as such is revealed both as ontical and ontological, and for this reason, the being of history, as the same-single and identical, should be understood as ontic-ontological, and just such an existence is called existential phenomenon. For this reason, the hermeneutical consideration of the existential phenomenon is principally realizable and is realized in this investigation and should be realized by the conception of phenomenological hermeneutics of historical texts and the meaning horizon provided 
by it.

Thus, it can be fixed that the wisdom of all sciences and concretely of the "science of history" of Movses Khorenatsi manifests itself and is interpreted by its dual components of "understanding" and "self-understanding" (or by pair modes of "self-understanding") perceived with its inner dichotomy and twofold unity.

3. Which is the third duality and in it genuinely own two-component of whole wisdom of the "science of history"? Which is the third dual category that in new and different way discloses the wisdom of "the science of history" in its inner duality, with its genuine and peculiar two-component of wisdom and the principal wholeness? In this study the wisdom of the history of Armenians of Movses Khorenatsi is presented and interpreted, and according to this implication of his teaching, also the wisdom of all possible (scientific) histories is principally presentable and interpretably disclosable for the fullness of its whole accomplishment carried also by its other dual categories, that express its twocomponent inner dichotomy and two-fold unity: first, in history contained substantive meaning and wisdom, that expresses the truth of "continual being" of nation's and people's self-identity, life and culture as such, and second, the wisdom, that constructs all these entities adequately understanding and interpreting the "theory of history".

And here, in the direct connection with the previous point, concretely the wisdom of the "science of history" of Movses Khorenatsi is studied by the dual categories of the above mentioned counsel of wisdom that reveal the truths, first, fulfillment of the Armenian identity, life and culture, second, of the "theory of history", and therefore the wisdom is perceived again by its inner dichotomy and twofold-unity. Let us note that the wisdom of the "science of history" is principally investigated and revealed by two fundamental aspects and, in essence, for each science, and also for social science and, in particular, for the science of history as such - by the twofold-unity of the own dual components. Each science is realized and manifests itself as a twofold content of its components, namely, - by dual components of its understanding and, in essence, - by knowledge of wisdom: first, searching that wisdom by which is just built the peculiar being of the universal and particular existence, by certain perception, division or dissection of the separated from the all existence as object and subject field of its research; and secondly, the wisdom by which is composed the becoming of the theoretical construction of the given science in its adequate openness and the capacity of cognition of the object of its investigation. Therefore, by the wisdom of the "science of history" of Movses Khorenatsi is meant, firstly, the wisdom expressed in the events of the past and present life, i. e. the revealing in the truth of the events of Armenian life the sense and meanings proclaiming and transforming to improved-order and wisdom of human self-identity, life and culture of contemporary readers and readers of coming generations, and secondly, the counsel of wisdom of the "theory of history itself".

4. In the Genesis story of the creation of man - by revelation, while in works of antic, later and contemporary philosophers, theoreticians of hermeneutics, while in particular sciences - by the investigation, from the oldest times it is well known that the nature of the being-in-world of man is spiritual-bodily. Together with human self-identity, the nature and 
being of human life and culture is also spiritualbodily. And if human self-identity and human life in this earthly world in its just spiritualbodily being its presence has by principally being alive and in it - by the self-completing spiritual life, the presence of culture is rationalsubstantial, and to the human personality and life-related intercomnection, by their being as such existence-forming significance culture is present in the sense of fulfilling its own genuine being by life-giving and providing spiritual enhancement.

So all human, social sciences and, in particular, history investigate human personality, life and culture as spiritual-bodily existence. In this study by querying and investigating the "wisdom of the science of history" as such and its particular embodiment in the "History of Armenians" of Movses Khorenatsi, it is thought up and critically pondered over by its significant presence for the spiritual-bodily twofold-unity being of human self-identity, life and culture. Here revealing that the wisdom of the "science of history" manifests itself in this world by its significance in relation to the twofold spiritualbodily unity pare of the nature of the being of man, his life and culture it can be fixed that it is manifested by its dichotomy and twofold-unity. Therefore in this article, the significance of the wisdom of the "science of history" in regard of spiritual-bodily pare of the composition of the human self-identity, life and culture are investigated just by the two components of its twofold-unity essence. The first component is the spiritual-life-enhancing significance of the wisdom of the "science of history" related to the spiritual-bodily unified being of these all. In this spiritual bodily unity as a leading substance, having in view just the principally subordinate co-being of the "body" or "substance" to the "soul", the second component is the soul-enhancing presence of the wisdom of the "science of history" for the spirituality of human self-identity, life and culture.

The first component is the soul-enhancing presence of the wisdom of the science of history together with the specificity of its purely spiritual significance in the human identity - for the rational soul, while in the life and culture - for the spiritual as such. The second component is the life-giving presence of the wisdom of the science of history in regard to all the above aspects of the spiritual-bodily unity co-existence.

5. Considering the science of history of Movses Khorenatsi, one should take into account that for the medieval thinker and scholar the understanding of the Existence, Universum is allembracing - things divine and human, while in contemplation and especially in theories of modern thinkers "all the existence" is not perceived by such a complete fullness of its all-embracing dimension. Herewith the medieval religious scholars sought the "divine" not only in purely divine things but also in human things, especially in the events and acts of human self-identity, life and culture. So Movses Khorenatsi investigating and narrating the truth of human things in his treatise - some measure of possibilities of goodordering, significant events and acts of human and concretely of Armenian life, in all these gives the possibility to perceive and understand the divine. In the problematics of investigation of the wisdom of his historical-scientific teaching or the "science of history" one has to understand the problem of revealing the narrated in his historical work fulfillment of human life, not only the invented by people according to their capacities for wisdom, but also the counsel or cove- 
nant of the divine wisdom accessible to human understanding. Herewith the medieval religious scholars sought the "divine" not only in purely divine things but also in human things, especially in the events and acts of human self-identity, life and culture. So Movses Khorenatsi also in his treatise investigating and narrating the truth of human things - some measure of possibilities of good-ordering, significant events and acts of human and concretely of Armenian life, in all these also gives the possibility to perceive and understand the divine. From the religious apprehension expressed on the numerous pages of the treatise of the faithful believer Movses Khorenatsi, it is possible to see, that the purposefully investigated and interpreted wisdom of his historiography is revealed by another general specificity - as the interwoven unity of human and divine. Therefore the wisdom of the "science of history" of Movses Khorenatsi also is manifested by its inner dichotomy and twofoldunity.

6. In philosophy arises a principle problem - to investigate the "particular-general or universal being". The science as such - in its genuine being - is adequate to its calling, only when it self-understands and becomes the science of "sense" and in it - of "wisdom", that reveals the truth of divine and human things or any particular sphere in "being of Entity". All science is an entity in its own mode of being and the essential problem is to investigate and study also the "being of the science". Following the revealed by M. Heidegger two-component philosophical query of "entity" and "being" (see Heidegger, 1962, pp. 19-28), the integral query of the "being of entity" and as such - also of the "being of all science" one can realize and find the principle unity by their twofold-unity.
History also is a peculiar entity with its own modus of being, and it is necessary to investigate the "being of history" or "history in its being". And the wisdom that is embodied and contained in the "being of history" or "history in its being" is manifested for history by its own twofold composition and with adequate and inner orderly interconnectedness of these components - by their twofold-unity. Which are these components? The wisdom of the "being of history" as such is revealed by its two-component composition: by the query of just the "history" - "What is the history?", "Which kind is history", "What for is the history?", and also by the query of the peculiarity of its being - "Which kind being has a history?" and also - "For what is its being"? By this kind explication of the problematics of the investigation of the wisdom of the "science of history" of Movses Khorenats, it becomes visible such twofold composition and twofold unity of the searching wisdom too.

7. Which is the seventh duality and in it the original own two-component unity of wisdom of the "science of history"? The intention and problematics of the given investigation with the inner mutual interwoven order is the following: to understand and interpretatively explicate the truth of the being of history as such and, in particular, the history of Armenians, and by that - the intrusted and conserved wisdom of the scientific conception of history of Movses Khorenatsi. By this formulation of the problematics of investigation denotes another - the seventh duality and also the own two-components of the wisdom of the "science of history", and here also is revealed the twofold-unity of the wisdom itself.

8. It should be noted when we query the wisdom of history or of the historical conception 
of self-identity, life and culture of human intelligent creature, the wisdom of all possible historical conceptions and, in particular, of the historiosophy of Movses Khorenatsi, there arises before us with its original and fundamental pair of general, inherent to the wisdom itself theoretical and practical components. Which are these inherent to the wisdom properties in the case of history?

It has been fixed above that in the historicalscientific conception of Khorenatsi is essential fundamental and form-building - the revelation of truth in the investigated past and present fulfilment. Here, the "truth" should be understood, first of all, as the truth of the essence, space and time, cause and result and other attributes, i.e. as the revelation of theoretical truth. The theoretical wisdom of history is that in history only theoretically, and in the case of Movses Khorenatsi also by the wisdom, revealed essence, causes and results, the deep meanings of events and human acts, and also their manifestation in the "theory of history" intelligible to their truth, are narrated "the meaning revealing truths" of the significant bygones, demonstrating to the reader the essence of the conceptual constructed theory having the ability of adequate understanding and interpreting them.

Together with the theoretical truth in the historical-scientific conception of Khorenatsi as another component of the single truth, it should be understood, comprehended and revealed the practical or active truth. The practical truth is the narrated sense of events investigated in the historical treatise of Khorenatsi, with the contained in it historical-philosophical and historical-scientific conceptions - in them themselves hidden and comprehending mysteries and explicitly expressed by the council (or covenant) of wisdom and also directing to the perfection potential more than 1500 years had "active" presence, and in the future also they'll have essentially-significant participation and inner influence in the life and culture itself of Armenians, in contemporary "philosophy of history" and the "science of history", in the present and future of the "theory of history".

In the conception of Khorenatsi history exists not only as a spiritual-theoretical cognition and science of fulfillment (a thing accomplished in the past and yet continuing its being in the present and future) for the Armenian selfidentity, life and culture, but also with its narrated content having dual significance for the educational perfecting progress of the human and just of Armenian self-identity and lifemode, this history exists as a spiritual-active science. In his treatise, narrating virtues of persons and their activities with praises and full disclosure, and vices - with reprehension and partial disclosure, history as such and, in particular, the Armenian history is presented interwoven with their theoretical forming, just as active history. In this sense, in the historicalscientific conception of Movses Khorenatsi the history appears not only as an intention of theoretical interest and the theoretical-scientific capacity but also as the human live activity itself and by that - the vital "decorating" active science, designed and aimed to cognition of goodness, by self-perfection for the good order of the separate and joint being of the human self-identity. In the historical-scientific conception of Khorenatsi, in the narration of essentially significant events and fulfillments aimed to understand and interpretavely explicate theoretical and practical wisdom, the history appears as a twofold-unity of the theoretical and the practi- 
cal. Summing up the above said and concluding, it can be fixed that in this study the wisdom of the "science of history" of Khorenatsi is interpreted also in its theoretical and practical inner dichotomy and twofold-unity.

9. In the direct connection with the previous point, the wisdom of the "science of history" of Movses Khorenatsi in this article is investigated and explicated not only by theoretical understanding of the truth (of the theoretical) and of good (of the practical), but also by practical activity or fulfillment, and by that the wisdom again appears by dual categories revealed by the inner dichotomy and twofold-unity of their components. Because the wisdom as such and, according to its calling, by its principle quality - not only the understanding of the truth and good (goodness), but at the same time making good in the soul-enhancing and life-creating good-meaning of their relation for the further improvement of the good-order of the human self-identity, life and culture. We have earlier presented to human rational soul, namely to the access to its theoretical and active capacity of wisdom a laconic formula of thought: "Wisdom is the perception and fulfilment of the truth (theoretical) and good (practical), to the best of human abilities" (Kocharyan, 2016 ${ }^{\mathrm{a}}$, pp. 16, 491, 508). One can see that following to the explication of the human self-identity, life and culture and the wisdom contained in them, to the critical and scientific investigation, historical thinking, the past and present comprehending and interpreting ponderings of Khorenatsi is inherent just such an understanding of wisdom. In his work together with the "theoretical" function of the history is principally emphasized to contemporary and future all "reading-lovers" and "learning-lo- vers" the significant "active" function of history, and for that in his narration Khorenatsi pursues to understand and interpret true spirituality in meaning revealing the truth of fulfilment of human self-identity, life and culture - by the presence in them of ingenious virtues and goodorder for humanity and humanness.

In regard to the above-suggested formula of wisdom available to human capacity it is necessary also to understand and fix: all that in the past events in the world, and in it - of the life, is genuine truth and goodness in the frame of their good-meaning in the eternal spiritual world, this is true as well in regard of the present and future.

It should be noted that these dual categories of theoretical understanding and practical fulfillment can be related not only to the "science of history", but also to the problematics of study and explication of wisdom, present in all human knowledge and in the science itself, revealing the truth, and by that opening also in this modus its inner dichotomy and twofold-unity.

10. As it was firmly stated in the previous two points, the human creature with his rational soul is cognitive and active, and by this unity of the theoretical-cognitive and practical lifeactive appears also the human life. Therefore the science also is called to life by need and intention both of cognition and action. In a certain degree of becoming a cognitive science, revealing the deep essence - "power" and "order" of things, namely, of "what" and "how" of the being of the investigated entity, and then by the already cognized and in some modus and measure to the fulfillment able its maturity the science also is active. One can fix also that the wisdom necessary and available in fulfilling the dual - theoretical and life-active - capacities of 
the human rational soul, by its destiny, appears and reaches the completeness of its truth by the unity of its theoretical-cognitive and life-active components.

In the above suggested formula of wisdom, by saying "truth" we mean not only that which is perceived as reliable "truth" in the concrete place and time of its fulfilled being, not only by certain human choice of actual being of "events and deeds", but also as potency, in which one can see "in what" and "how" actualized being could be with another choice, concretely in such fulfilling, which follows the authentic calling adequate for the being of these "deeds and events". In the history of Movses Khorenatsi and embodied in it historical-scientific conception just by this understanding of the truth become principally possible, necessary, preferable and "pre-chosen" all those ponderings, in which are fulfilled "evaluating judgments" about thoughts and deeds - by their praising and condemning meanings that in modern science are called "value-judgments" and from the times of M. Weber are differentiated from "science judgments". The approach exposed later, in essence, does not inherit and by that is not the heir of the historical-philosophical truly scientific principle of Khorenatsi: by accordance or nonaccordance of the being of events and fulfilment of human deeds to its genuine destiny to define their true or untrue being.

The "truth" presents itself to the "cognitive" and "active" human nature as a twofold unity, in which are unity-interlaced present the "ontological truth", which is appearing and defined in accordance and/or non-accordance with its genuine destiny, the truth of the concretely actualized its being, and the "teleological truth", which is appearing as the preferable in the perspective of the good-ordered being of the world and life in the problematics of the forthcoming human activity. Truly, for the explication of the nature or truth of genuine being and the revealing its sense and wisdom humanitarian, social and cultural being, among them also of "history", one must have in view, that in the "unified truth" together with the Gadamer's (1960) "truth of being" there is another component too (see Kocharyan, 2006, pp. 190-194). In psycho-physical phenomena human life is lifegiving and soul-enhancing, therefore also for the historical, and as such - for all human and social investigations, is essential the formulated in contemporary hermeneutics Ricoeur's “teleological truth", the truth by which one can be and preferably should be goal-directed in his life (see Kocharyan, 2016 a , p. 510; Kocharyan, $2016^{\mathrm{b}}$, p. 132). To the preferable being directing teleological truth is present in realities of life, and is duly called to present to their theoretical investigation and then by its essential significance also active good-order seeking theory and science in their present and future. And it should be noted, that in wisdom, i.e. in just science of the truth and good, by the interwovenness of these two - the truth of being and the teleological truth, it is possible to reach genuine and perfect completeness of the truth, at the best of human ability. It is explicated in all the exposition of my above-cited monograph that such an all-uniting understanding and concept of "truth" leads Movses Khorenatsi in his investigating query and search of history, and in it and with it just of the wisdom, and his answer to this query - in the "History of Armenians". The essence of the question, the gist that is searched and the answer of the historical investigation of Khorenatsi and by the above-cited 
monograph the history and other relevant phenomena are considered and cognized both by the truth of being and the teleological truth, only this two-fold unity making possible to reach the all-embracing holistic truth, at the best of the human ability, striving by perceiving intention and fulfilment.

The true calling of all human and sociological science, as theoretically cognitive and life-active - doing just the good and the goodness, and by this - is to be life-creating and fulfilling the good-order of the human self-identity, life and culture. Because all the human science and in particular historical science is called to life by the need and perceiving intention of the good-order of human self-identity, life and culture. Meanwhile, all the human and sociological science, and also historical science studying realities - the past and the present, and namely the order of their being, critically meditates all over, firstly, in statics of their being - in the given interval of time, and secondly, in the dynamics of their presence (in the case of some things - during the time of their stable functioning), and secondly, in dynamics of their becoming and change, therefore by this inter-complementing duality disclosing and revealing the truth of the being itself, about the fulfilment of all as the knowledge gains only the theoretical truth.

Father of Armenian History considers everything from the viewpoint of the query of the true potential of their being and factual fulfilment: in the historical-philosophical or historical-social investigation, the reviewed given phenomenon has been factually realized according to its vocation and destiny and the true potential of its necessary and preferable and pre-chosen being?
We have realized the same query also in regard of the "history" itself: the history in itself and/or by itself "narrated", and also in its "modus of narration" has been actually realized according to its destiny and true potential of its necessary and preferable and pre-chosen being? According to such way explicated conception, in their true being, therefore also in their own being, is disclosed the sense and wisdom of the being of all phenomena and, in particular, history. One of the fundamental points of this conception is that all these phenomena and in particular the "history", in accordance to its destiny, become in their own being only due to their "What?" and "How?" becoming and staying in the "present" and fulfilled, at the best of human ability, true, good and just life-giving divine wisdom, without which reside only in an elusive, untrue and not-own being of human selfwill. It is essential to fix also that for the successive explication of the truth of the hermeneutical experience of the "science of history" of Khorenatsi the principle, and categorical meaning of this statement is characteristic for the universality of its theoretical and practical application.

Father of Armenian History narrating the good-meaning and evil-meaning events of the past and thus drawing the picture of possibilities of becoming of the self-identity, the way of life and culture, and also of all that perfecting good, and also of all that braking evil, inherits, edifies and exhorts the "reading-lover" and "learninglover", in comparison with the happenings, the refusal of the evil-meaning and the life-braking, and similitude in the fulfilled good-meaning and good-ordered counsel. In his treatise the principal needs of the Armenian self-identity, life and culture and as the answer to them - the aspiration, understanding of the forthcoming 
deeds and of the deeds of the past generations and contemporaries, and also of the produced by the state of things in whole, are considered and thought over in comparison with the following two fundamental ideas - "justice" and "humanity".

In the life of human generations in this or another extent of understanding and fulfilment of "humanity" is created a certain normative system. Expressing this in more detail, it could be fixed, that in the life of humanity in the certain form and extent by understanding "love of God" and "love of mankind", sometimes (and quite often) by forgetting the first and not always considering the first in regard of the second and thus correcting by it, is acting a system of moral order and is created some perception of "justice", and in a lesser degree, as a demonstration of collective will of the human race and society, are created judicial laws and norms. It can be established by the human history that the deeper understanding of "humanity" changes the perception of "justice" and the system of law called to put in order the life of people with all its manifold content. According to Christian wisdom, humanity reaches the perfection of its completeness in the "love of each other by God": "to love people so as loved and precepted our Lord Jesus Christ". And in human life, the "humanity" - by its growing understanding and fulfilment - is that fundamental idea and factor which brings to perfection in human life the "present" or the established "justice" to the divine "justice", to the perfect completeness of justice.

Movses Khorenatsi in his history narrating the affairs and orders of life in all times, and in particular, narrating about Tigran, Vagarshak the Sage et al. - explicitly, and in some other places - implicitly, makes perceivable the dual categories of wisdom - "justice" and "humanity", directing and bringing it to the perfection and completeness the wisdom called to fulfil in human self-identity, life and culture. Thereby, the wisdom of the "science of history" of Khorenatsi, in essence, getting interlaced in history itself by ideas of "humanity" and "justice", the complete truth of human and concretely of the Armenian self-identity, life and culture with its "existential" and "teleological" components once again appear by their inner dichotomy and twofold-unity.

11. In the world and in life, human beings, in the all-embracing vital activities - thoughts, words and acts - significant importance belongs to the principle need of understanding and acting by the necessary and preferable (pre-selected) wisdom accessible to human's capacity. In the "science of history" of Khorenatsi by the dual categories "necessary and preferable" are considered both the objective content of history and his understanding and interpreting "theory of history". These dual categories have also their use and a thorough presence in the previous points of the explicated by dual categories of components of wisdom. Thus, the wisdom of the "science of history" appearing in the above said third point - as the investigated "realities of the life and culture" and the "theory of history", in the fourth point - as the essentially significant for the "soul" and "body" categories of the "soullivingness" and "life-creativeness", in the sixth point - as "historical entity" and its "being", in the seventh - as the "narrated content" and "modus of narration", in the eighth - as the "theoretical" and "active" ("practical") and as such "truth" and "good" (goodness), in the ninth historical "understanding" and active "fulfill- 
ment", and by that appearing just as denotats of the dichotomic and twofold-unity of wisdom, one should principally study all them again in the light of the components of dual categories "necessary" and "preferable" ("pre-chosen"). Hence the wisdom of human, social sciences, and in particular the "science of history" can be explicated also by such inner dichotomy and just twofold-unity of its presence in human affairs.

12. In this study, the wisdom of the "science of history" is embodied and interpreted also by dual capacities of the rational soul, namely by belief and thought, reachable and presumable sense, that reveal the counsel and covenants of wisdom present in these meanings - by their dichotomy and twofold unity.

Truly, in the text of the famous treatise of the Father of Armenian History, in its narration by the inter-connected weaving, together with the sense and meaning and in it - the wisdom, revealing the truth of mentally comprehended things, everywhere are co-present the sense and counsel and covenant of wisdom, revealing the truth of belief. The information handed over to the treatise of Khorenatsi to be preserved in it and by that becoming accessible to the "learninglover-readers": the truth of Armenian identity, life and culture, and also revealing and interpreting its sense has manifold content. His treatise "History of Armenians" is a history interwoven by the principle of Christian theology.

According to Christian theology, mankind's rational soul reaches wisdom by his ability of belief and thought. And there is no contradiction between the "truths of faith" and genuine science, but only peace and inner unity. The unity-whole wisdom is complementary unified-interwoven by the access to human capacity "wisdom of faith" and wisdom of the "truths of thought".

History is born and has its existence in human life by understanding and interpreting of the past of human identity, life and culture. By means of reasoning, understanding and interpretation being born in dens concreteness and substantially significant fulfilment of the world's unique genesis and in it - of a genuine and essential event and presence of the spiritual-bodily essence of human self-identity, life and culture, history by understanding becomes spiritual. It should be said, that history just by understanding had been transformed into a spiritual sense and wisdom, selfrealizing and self-asserting into its own spiritual nature.

The genuine goal and truth, the true and complete results of this type of human activity, like the sciences - from all or from the significant fulfillment and of the past of human self-identity, way of life and culture - the possible fruits of human comprehension and liferealization of all the wisdom (of the goodmeaning of truth and goodness) in the life of readers of contemporaries and past generations. Thus, the understanding and fulfilment of the truth and good, at most of human ability is just the accessible wisdom of all human selfidentity and humanity. Therefore in work "History of Armenians" of Movses Khorenatsi and in the contained in it historical-scientific conception the truth of Armenian history appears as an interpreting explication in all past Armenian selfidentity and life-beautification, problems of life and culture - happened and fulfilled in a concrete time and place - raising and also in its present and future preferable wisdom, "totally and allembracing applicable for humanity" virtues, dignities and good-social-order. As such, his theory 
of history and his historical-scientific conception is revealed as philosophizing "science of history".

\section{REFERENCES}

Ackrill, J., (1963). Aristotle, Categories and De Interpretatione. Oxford: At the Clarendon Press.

Aristotle, (1963). Categories. Oxford: Clarendon Press.

Aristotle, (2006). Metaphysics. Oxford: Clarendon Press.

Carr, B., (1987). Metaphysics: an Introduction. Atlantic Highlands, New Jersey: Humanities Press International.

Gadamer, H.-G. (1960). Wahrheit und Methode. Tubingen: J.C.B. Mohr (Paul Siebeck).

Grossmann, R., (1983). The Categorial Structure of the World. Bloomington, Indiana: Indiana University Press.

Heidegger, M., (1962). Being and Time. N. Y. and Evanston: Harper \& Row Publishers.

Hoffman, J., \& Rosenkrantz, G. S., (1994). Substance among other Categories. Cambridge: Cambridge University Press.

Kant, I. (1958/1781). Critique of Pure Reason. (N. K. Smith, Trans.) London: Macmillan.

Khorenats'i, M. (2006). History of the Armenians. Ann Arbor, Michigan: Caravan Books.

Kocharyan, R. (2006). Hans-Georg Gadameri pilisopayakan hermen\&tikan. (Philosophical Hermeneutics of Hans-Georg
Gadamer, in Armenian). Yerevan: GAT.

Kocharyan, R. (2016 ). Patmut'yuny' \& hermen\&tikan. Girq 1. Movses Xorenacu patmagitakan hayecakargy'. (History and Hermeneutics. Book 1: HistoricalScientific Conception of Movses Khorenatsi, in Armenian). Yerevan: Matenadaran, Printinfo.

Kocharyan, R. (2016 ). Patmut'yan meknoxakanut'uny' \& Movses Xorenacu patmagitakan hayecakargy. Mas 1: Patmut'yuny' jhamanakahos kyanqi ancyali mshakutoren nshanakali nerkayut'yu$n y$ '. (Interpretativity of History and the Historical-Scientific Conception of Movses Khorenatsi, part 1: History as Culturally Significant Presence of the Past of Transient Life, in Armenian). Vem Pan-Armenian Journal, 1(53), 110-137.

Paton, H. J. (1936). Kant's Metaphysic of Experience. London: George Allen and Unwin.

Studtmann, P. (2007). Aristotle's Categories. The Stanford Encyclopedia of Philosophy (Fall 2008 edition). (E. N. Zalta, Ed.), Retrieved March 1, 2019 from: https://plato.stanford.edu/archives/fall2 008/entries/aristotle-categories.

Thomasson, A. (2018). Categories. The Stanford Encyclopedia of Philosophy (Spring 2018 edition), (E. N. Zalta, Ed.), Retrieved March 3, 2019, from: https://plato.stanford.edu/archives/spr2 $\underline{018 / \text { entries/categories }}$ 